\title{
Introducing sustainable development with a mathematical model
}

\author{
James Keirstead \\ BSc, MSc, DPhil, CEng MEI \\ Lecturer, Department of Civil and Environmental Engineering, Imperial College London
}

Skempton Building, Imperial College London, London, SW7 2AZ,

tel: +44 (0)207 594 6010, email: j.keirstead@imperial.ac.uk

Word count: 3034

Figures: 0

Submitted: 2 December 2013

Proceedings of the ICE: Engineering Sustainability

http://dx.doi.org/10.1680/ensu.13.00036 


\begin{abstract}
The role of the professional engineer has shifted over time from the application of narrowly defined technical expertise to a more holistic contribution to the betterment of society. However as the profession has sought to develop these 'habits of mind' in engineering students, it has become apparent that both students and faculty find it difficult to transition from traditional technical subjects to the often nebulous realm of sustainability. This paper introduces a simple mathematical model based on a Cobb-Douglas production function to show how key principles of sustainable development can be introduced to students in a familiar setting. Examples are provided of how the model might be incorporated into an overall sustainability curriculum, emphasising the model's role not as a predictive calculating tool but as a conceptual framework through which sustainability can be explored and better understood.
\end{abstract}

\title{
Notation
}

D level of development

E environmental capital

$S \quad$ social capital

K economic capital

$t$ time

\section{Keywords}

Education and training

Sustainability

Mathematical modelling 


\section{Introduction}

In a survey of the history of civil engineering, Jowitt (2004) remarked upon the discipline's transition from one that thrived on local problems tackled with "technical rationality" to one which is increasingly asked to deal with systemic 'wicked' problems. These large-scale multi-disciplinary challenges, like climate change or urbanization, defy narrow technical solutions and consequently require engineers "to be more fully aware of the economic, social and environmental dimensions of their activities and more skilled in meeting their objectives" (p. 87). The article emphasised the need to reform engineering education so that the concept of sustainable development was integrated into mainstream training in order to develop "an appropriate habit of mind, attitudes, systems skills and domains of knowledge to enable the engineers of the future to better contribute to society". These recommendations, arising from an Institution of Civil Engineers Task Group, have since been widely adopted by the engineering profession, both in the UK and overseas (e.g. RAE 2005; Engineering Council 2013; JBM 2013).

However it remains an open question how best to translate these ambitions into practice. The Joint Board of Moderators, responsible for accrediting engineering education in the UK, has provided a number of recommendations in this regard, for example, asking that an explicit sustainability thread run through degree programmes with an increased focus on related coursework and the economic and social aspects of sustainability (JBM 2011). Furthermore, the JBM and Royal Academy of Engineering have initiated an exercise to produce guidance for lecturers on embedding sustainability in undergraduate engineering courses. This has led to a brief report that outlines nine core principles that lecturers can incorporate into their own teaching, along with examples of best practice (Broadbent 2012). Alongside these changes in the undergraduate curriculum, a number of universities also offer specialized sustainable development programmes for engineers particularly at the post-graduate level (Kamp 2006; Fenner et al. 2005; Perdan et al. 2000; Fisk \& Ahearn 2006).

Arguably the biggest challenge for those seeking to teach engineers about sustainable development is to persuade both students and faculty that it belongs alongside more traditional curriculum. As Jowitt 
(2004, p.79) says, "Engineers are not comfortable —and rightly so-with the idea of a profession which eschews rigour." Having been trained in this way, how are engineers supposed to respond when presented with "sustainable development", a concept which - with apologies to the Brundtland Commission - is widely critiqued for lacking a clear definition (Hopwood et al. 2005)? A worldwide survey of engineering students indeed confirms that they have difficulty making links between general sustainability theory and the detail of engineering practice (Azapagic et al. 2005). Even textbooks that emphasise the softer sides of sustainability seem to struggle with clearly communicating the practice of sustainable development (Fisk 2011), and those with an engineering focus rely primarily on textbased narratives to develop key concepts, which are arguably off-putting for those more at home with equations (Allenby 2011).

This paper therefore explores one potential strategy to ease the transition from core engineering disciplines to the messy world of sustainable development: the use of a simple mathematical model that captures core concepts. While engineers may tend to think of mathematical models as codifications of immutable natural laws, other disciplines - in particular, economics - use mathematical models extensively as conceptual models, as ways of thinking about problems that are significantly messier than a neat equation might initially suggest. As a starting point, I assume that the students of interest here are upper year undergraduates or graduate students; that is, engineers with a good grounding in the basic technical subjects of the discipline and beginning to encounter sustainability either through dedicated taught modules, problem-based learning, or their own reading and experience.

\section{The pedagogical value of mathematical models}

An important feature of an undergraduate engineering degree is an increased maturity and confidence with mathematical modelling. Whereas a final year school student might be expected to memorize an equation like $F=m a$, undergraduates are gradually taught to derive such models from first principles, experimental data, and a growing body of experience. For example, this might mean writing and 
solving the balance of forces in a static structure, where the geometry of the particular system will vary from problem to problem. However the theory underlying such models is still presented essentially as a fact to be memorized; it is only much later in post-graduate education that a student is expected to derive equations based on new theoretical understandings of a physical system.

While this serves the "technical rationality" of basic engineering practice well, it does stand in stark contrast to the mathematical models used in other disciplines, notably economics. As Gilboa et al. (2011) note, economic models are often highly stylised representations of a system that draw heavily on theoretical innovation. In other words, the heavy lifting of economic models is not in the mathematics per se but in the framing of the problem, formalised by mathematical equations (see Arrow et al. 2011 for a selection of such models). This tradition has of course led to substantial critiques of economic models: that they yield poor predictions, that they are just as likely to reflect the modeller's political and other interests rather than any 'objective' description of the problem, that they adopt assumptions that have been empirically shown to be false. But Gilboa et al. argue that this is largely a misunderstanding, that good economists recognize these limitations but use mathematical models in a perfectly valid manner as " 'theoretical cases', which help understand economic problems by drawing analogies between the model and the problem....[E]conomic models, empirical data, experimental results and other sources of knowledge are all on equal footing, that is, they all provide cases to which a given problem can be compared." (p. 1).

This kind of mathematical modelling is not uncommon in the wider sustainability literature. Consider the IPAT framework, which decomposes environmental impact $I$ into the product of three drivers: population $P$, affluence $A$, and the level of technology $T$ (Ehrlich \& Holdren 1972; Commoner 1972). The Kaya identity is a similar well-known expression for decomposing global carbon dioxide emissions into the product of population, affluence, energy intensity, and carbon intensity.

These particular equations are restricted to environmental impacts, and therefore they lack generality when dealing with sustainable development overall. In contrast, Phillips (2009) offers a more elaborate model of sustainability grounded in earth systems science: 


$$
S(t)=E(t)-H_{N I}(t)
$$

where $S(t)$ is sustainable development at time $t, E$ is the environment, and $H_{N I}$ represents human needs. Each term of the model is duly expanded and differential equations are used to examine the dynamic relationships between human society and the environment. The model offers insight on potential sustainable 'operating' strategies for the global environment, as well as being applied in a detailed analysis of Bangalore Metro System. However the model is strongly linked with the notion of environmental carrying capacity, and does not include social or economic influences.

\section{The model}

The above literature suggests that a simple mathematical model could be a valuable tool for providing a theoretical understanding of sustainable development using a rigorous language familiar to undergraduate engineers. The model that follows therefore emphasises pedagogy over calculation and to that end, three specific sustainable development concepts are prioritised:

- What is development and how can it be measured?

- The three capitals, i.e. social, economic, and environmental, and their role in development

- Choosing system boundaries and the role of innovation, as illustrated by efficient resource use

\subsection{What is development?}

We start with a basic equation and a question:

$$
D=f(\boldsymbol{X})
$$

where $D$ is development and $\boldsymbol{X}$ is a vector of factors that affect development through some unknown function, $f($.$) . The question is simple: what is development? This can be used to stimulate a$ discussion which, in my teaching experience, tends to elicit widely differing views about what should be prioritised. For example, those from a developed country background may emphasise the importance of environmental protection, whereas those from a developing country often stress the 
need for basic human and economic development. This approach introduces two of Broadbent's (2012) nine principles of sustainable development: an emphasis on learning from other stakeholders and understanding different perspectives. The conversation can also be steered to engage with Principle Eight "Emphasise a Commitment to Professional Values", as students can be presented with alternative definitions of the engineering profession and asked to decide how their definitions of development fit with that professional duty.

A related question prompted by the mathematical formulation is how to measure development. This can stimulate a review of existing development metrics, such as the UN's Human Development Index or the Stiglitz report on the efficacy of GDP as a measure of social progress (Stiglitz et al. 2009). Related indicator techniques, such as multi-criteria decision analysis, can also be introduced at this point.

Note that we have not yet said anything about sustainable development. However, with the further assumption that $D$ is a function of time, we can write a simple zero-order differential equation to define sustainable development, which of course is reminiscent of the Brundtland definition:

$$
\frac{d D}{d t} \geq 0
$$

Hopefully by now the brighter students in the class should be asking whether $D$ is a per capita quantity or an aggregate measure. This is an excellent opportunity to reflect on classical sustainability concepts such as inter-generational (or even inter-species) equity (Haughton 1999) since we should be interested in neither the sum, nor the mean level of development, but its distribution. For simplicity, the model adopts the assumption that $D$ is an aggregate metric although exercises can be introduced to illustrate how the properties of a distributed variable might be summarized (e.g. calculating the Gini coefficient). 


\subsection{The three capitals}

With the left-hand side of (1) sorted out, the next question is the mystery function $f$. The goal here is to choose a functional form that is both plausible and instructive. To this end, the Cobb-Douglas production function is an ideal solution such that:

$$
D=a S^{\alpha} K^{\beta} E^{\gamma}
$$

where $a$ is a constant (equation (3) could be written a proportional statement omitting this constant to avoid confusion), $\alpha, \beta$, and $\gamma$ are model-fit parameters (ignored at present), and $S, K$, and $E$ represent social, economic, and environmental capital stocks respectively (these can also be treated as functions of time, like $D$ ). This particular formulation satisfies the plausibility criteria as it has been experimentally validated in a range of economic applications and the simple multiplicative relationship is easy to understand.

The instructive value of the Cobb-Douglas formulation primarily comes by allowing one to explicitly highlight the potential roles of social, economic, and environmental capital in delivering development. For example, one can introduce general notions of a capital stock as a pool of resource from which flows can be added or subtracted, flows which facilitate desired outcomes. Starting with a simple onecapital stock model for example, one could again differentiate with respect to time to see how satisfying the sustainable development condition (2) requires increasing or maintaining the level of these capital stocks. Furthermore by introducing multiple forms of capital, one can begin to discuss the complex trade-offs and substitution effects that exist between capital stocks. For example, one can explore notions of 'strong' versus 'weak' sustainability (Neumayer 2003). These trade-offs encourage students to assess their own values and beliefs about what is truly important and worth sustaining and if illustrated with practical examples (for example, contrasting the UK and Norwegian allocation of North Sea oil revenues) enables students to practice Broadbent's Principle Seven "Apply Judgement to Real Problems.” 


\subsection{System boundaries and innovation}

Sustainable development is largely about taking a systems view of an engineering problem and trying to anticipate how an initially attractive technical solution might be undermined by liabilities displaced beyond in the original temporal or spatial boundaries of the analysis. Using the model, this can be illustrated with the example of resource depletion.

Using a simplified version of (3), we could write that development depends solely on the consumption of an environmental capital stock $\Delta E$, rather than the total stock $E$ :

$$
D=a \Delta E^{\gamma}
$$

$E$ might therefore represent fossil fuel energy resources or land area. If we assume that there exists some finite amount of this resource $E_{0}$ available at time $t=0$, then the following constraint can be written:

$$
\int_{t=0}^{T_{\max }} \Delta E(t) d t \leq E_{0}
$$

Students can be prompted to ask what is an appropriate choice for the system boundary, in this case the maximum time $T_{\max }$. Historical examples can help to illustrate the consequences of such constraints, such as the way in which the depletion of the England's forests in the seventeenth century led to a spatial expansion of the system boundary through increased timber trade with the Baltic region and the Americas, and the substitution of charcoal by newly discovered fossil fuel reserves. The role of engineers can be developed further by exploring how they might intervene in this stylised system to ensure continued performance for $t>T_{\max }$. With a few additional manipulations, the importance of continual innovation can be highlighted. This is often one of the most difficult things for students to appreciate, although recent examples like the shale gas revolution in the United States help to illustrate the point that, while resource depletion looks unavoidable under current circumstances, the real question is whether rates of innovation and the flexibility of system boundaries will be sufficient to 
avoid these constraints. Similar points are made with a simple mathematical model by Bettencourt et al. (2007) and in Tainter's well-known studies of collapse in complex civilizations (Tainter 1988).

\section{Applying the model in curriculum design}

To reiterate, the goal of this model is not perfect representational accuracy but to provide a framework that uses rigorous methods familiar to engineering students as a way of gradually introducing sustainable development. Clearly at some point, trying to shoehorn additional concepts into this model will become unwieldy and so this section provides a number of curriculum design recommendations for its effective use within a broader course of study.

\subsection{Learning objectives}

Learning objectives are statements of what a student is expected to have accomplished or what skills they should have acquired following a learning programme. It is suggested that the model should be introduced as part of the learning objectives, explicitly noting its value as a conceptual framework for thinking about sustainability. For example, an overall module objective might be: "At the end of this module, students should be able to apply a simple mathematical model of development to critically assess the sustainability of an engineering project." Equally for a single lesson, "At the end of this lecture, students should be able to explain the concept of the "three capitals" in words and mathematically."

These objectives should of course align with the overall aims of the module which are likely to remain high-level, as in the Engineering Council's guidance that chartered engineers should "undertake engineering work in a way that contributes to sustainable development" (Engineering Council 2013).

\subsection{Syllabus and recommended reading}

The JBM (2013) provides a number of specific recommendations for the syllabus of the sustainability components of engineering degree programmes including specific topics such as energy, waste, and water management, life-cycle assessment methods, carbon accounting, and options assessment. As 
illustrated above, the model provides a framework through which many of these concepts and methods can be introduced. Perhaps the most significant change to the syllabus of a sustainability programme that is suggested by the model is a greater emphasis on economics, in particular notions of substitution and innovation. There is a wide literature available from which examples can be drawn, including William Nordhaus's work on resource economics and critiques of the limits to growth model (Nordhaus 1973; Nordhaus 1992) and Eric Neumayer's work on indicators of sustainable development (Neumayer 2003; Neumayer et al. 2005). Encouraging students to investigate this literature explicitly addresses two of Broadbent's principles: to take learners out of their comfort zones and to learn from other disciplines.

\subsection{Learning and teaching methods}

The use of the model is compatible with traditional engineering learning and teaching methods such as lecturing, tutorials, and self-study problem sheets. To aid the transition from traditional analysis to sustainability analysis, one might therefore design a series of tutorials in which the learner starts out performing fairly standard manipulations of the model (e.g. fitting it to data, making simple predictions of future behaviour with a given functional form, etc), but then gradually introducing complications (e.g. using the model to perform a calculation based on a case study which is then contradicted by some real-life factors not in the model). Ultimately, the students should engage in problem-based learning, applying the model as they see fit to understand the problem and assess potential solutions.

\subsection{Assessment}

Assessment should reflect the learning objectives and therefore it is suggested that examinations or other assessed work focus more on the use of the model as a conceptual model, rather than evaluating mathematical skill. In the sample learning objective provided earlier, it was suggested that students use the model to "critically assess" a project's sustainability. This is a very open-ended question and 
gives the student a chance to draw in complementary material which they have explored elsewhere in the curriculum.

\section{Conclusion}

Engineering students at both undergraduate and post-graduate level are increasingly being asked to learn about sustainable development, both as a guiding principle for professional practice and as an umbrella term for a set of specific analytical tools like life-cycle assessment. However as the profession has sought to introduce these changes, it has become apparent that one of the greatest challenges is to introduce students trained in rigorous technical disciplines to the rather subjective notion of sustainability.

This paper has sought to overcome this problem by drawing on the use of mathematical models in economics, where such models are used primarily as theoretical tools to build understanding of complex problems. Using a standard Cobb-Douglas production function and basic calculus, it was demonstrated that a number of core sustainable development principles such as the goal of development, three capitals analysis, and system boundaries can all be explored. Recommendations were also provided for how the model can be incorporated into different stages of a curriculum to ease the tradition from 'hard' engineering to the 'softer' science of sustainability.

\section{References}

Allenby, B.R., 2011. The Theory and Practice of Sustainable Engineering, Pearson Education. Available at: http://www.amazon.co.uk/The-Theory-Practice-SustainableEngineering/dp/0273752162 [Accessed April 10, 2013].

Arrow, K.J. et al., 2011. 100 Years of the American Economic Review : The Top 20 Articles. American Economic Review, 101(1), pp.1-8. Available at: http://pubs.aeaweb.org/doi/abs/10.1257/aer.101.1.1 [Accessed February 10, 2011].

Azapagic, A., Perdan, S. \& Shallcross, D., 2005. How much do engineering students know about sustainable development? The findings of an international survey and possible implications for the engineering curriculum. European Journal of Engineering Education, 30(1), pp.1-19. 
Available at: http://www.tandfonline.com/doi/abs/10.1080/03043790512331313804 [Accessed April 10, 2013].

Bettencourt, L.M.A. et al., 2007. Growth, innovation, scaling, and the pace of life in cities.

Proceedings of the National Academy of Sciences of the United States of America, 104(17), pp.7301-6. Available at: http://www.ncbi.nlm.nih.gov/pubmed/17438298.

Broadbent, O., 2012. Embedding Sustainability in Undergraduate Civil Engineering Courses: A Practical Guide, London.

Commoner, B., 1972. A Bulletin Dialogue on "The Closing Circle", Response. Bulletin of the Atomic Scientists, 28(5), pp.17,42-56.

Ehrlich, P.R. \& Holdren, J.P., 1972. A Bulletin Dialogue on "The Closing Circle", Critique. Bulletin of the Atomic Scientists, 28(5), pp.16,18-27. Available at:

http://books.google.co.uk/books?id=pwsAAAAAMBAJ\&pg=PA16\&lpg=PA16\&dq=A+Bulletin + Dialogue + on $+\% 22$ The + Closing + Circle $\% 22,+$ Critique \& source $=$ bl\&ots=zn04SSU70X \& sig=Q ULAthNoK7aqSSy515kyQgy_ai4\&hl=en\&sa=X\&ei=dSP5UNDTAYaK0AW-

84DYCQ\&redir_esc=y\#v=onepage\&q=A Bulletin Dialogue on \%22The Closing Circle\%22\%2C Critique $\& \mathrm{f}=$ false.

Engineering Council, 2013. UK Standard for Professional Engineering Competence, London.

Fenner, R.A. et al., 2005. Embedding sustainable development at Cambridge University Engineering Department. International Journal of Sustainability in Higher Education, 6(3), pp.229-241. Available at: http://www .emeraldinsight.com/10.1108/14676370510607205 [Accessed March 8, 2013].

Fisk, D., 2011. Sustainability education: perspectives and practice across higher education, edited by Paula Jones, David Selby and Stephen Sterling. International Journal of Ambient Energy, 32(2), pp.111-111. Available at: http://www.tandfonline.com/doi/abs/10.1080/01430750.2011.584709 [Accessed April 10, 2013].

Fisk, D.J. \& Ahearn, A., 2006. Creating policy analysis skills in postgraduate engineering for sustainable development. Journal of cleaner production, 14(9-11), pp.946-951. Available at: http://www.sciencedirect.com/science/article/B6VFX-4JFHDYN1/2/861b86763bb80077ca87f671f0731fb4 .

Gilboa, I. et al., 2011. Economic Models as Analogies. SSRN Electronic Journal, pp.1-31. Available at: http://www.ssrn.com/abstract=1979472 [Accessed January 10, 2013].

Haughton, G., 1999. Environmental Justice and the Sustainable City. Journal of Planning Education and Research, 18(3), pp.233-243. Available at: http://jpe.sagepub.com/cgi/content/abstract/18/3/233 .

Hopwood, B., Mellor, M. \& O’Brien, G., 2005. Sustainable development: mapping different approaches. Sustainable Development, 13(1), pp.38-52. Available at: http://dx.doi.org/10.1002/sd.244 .

JBM, 2011.2010 Annual Report, Available at: http://www.jbm.org.uk/uploads/JBM101_AnnualReport2010.pdf. 
JBM, 2013. Annex C - Sustainability in Degree Programmes, Available at: http://www.jbm.org.uk/uploads/JBM123_AnnexCSustainability.doc2013.pdf.

Jowitt, P.W., 2004. Sustainability and the formation of the civil engineer. Proceedings of the ICE Engineering Sustainability, 157(2), pp.79-88. Available at: http://www.icevirtuallibrary.com/content/article/10.1680/ensu.2004.157.2.79 [Accessed April 10, 2013].

Kamp, L., 2006. Engineering education in sustainable development at Delft University of Technology. Journal of Cleaner Production, 14(9-11), pp.928-931. Available at: http://linkinghub.elsevier.com/retrieve/pii/S0959652606000308 [Accessed March 8, 2013].

Neumayer, E., 2003. Weak versus Strong Sustainability: Exploring the limits of two opposing paradigms 2nd ed., Cheltenham: Edward Elgar.

Neumayer, E., Tietenberg, T. \& Folmer, H., 2005. Indicators of sustainability. In Cheltenham: Edward Elgar, pp. 139-188.

Nordhaus, W.D., 1992. Lethal Model 2: The Limits to Growth Revisited. , (1971). Available at: http://www.brookings.edu/ /media/Files/Programs/ES/BPEA/1992_2_bpea_papers/1992b_bpea _nordhaus_stavins_weitzman.pdf.

Nordhaus, W.D., 1973. The Allocation of Energy Resources. Human Ecology, 2(January), pp.1-22. Available at: http://www.brookings.edu/ /media/Files/Programs/ES/BPEA/1973_3_bpea_papers/1973c_bpea_ nordhaus_houthakker_solow.pdf.

Perdan, S., Azapagic, A. \& Clift, R., 2000. Teaching sustainable development to engineering students. International Journal of Sustainability in Higher Education, 1(3), pp.267-279. Available at: http://www.emeraldinsight.com/10.1108/14676370010378176 [Accessed April 10, 2013].

Phillips, J., 2009. The advancement of a mathematical model of sustainable development. Sustainability Science, 5(1), pp.127-142. Available at: http://www.springerlink.com/index/10.1007/s11625-009-0103-3 [Accessed August 5, 2012].

RAE, 2005. Engineering for Sustainable Development : Guiding Principles, London. Available at: http://www.raeng.org.uk/events/pdf/Engineering_for_Sustainable_Development.pdf.

Stiglitz, J.E., Sen, A. \& Fitoussi, J.-P., 2009. Report by the Commission on the Measurement of Economic Performance and Social Progress, Paris. Available at: http://www.stiglitz-senfitoussi.fr/en/index.htm.

Tainter, J.A., 1988. The Collapse of Complex Societies, Cambridge: Cambridge University Press. 